\title{
Neuronal injuries in cerebral infarction and ischemic stroke: From mechanisms to treatment (Review)
}

\author{
YUNFEI ZHAO $^{1 *}$, XIAOJING ZHANG ${ }^{2 *},{\text { XINYE } \mathrm{CHEN}^{2,3} \text { and YUN WEI }}^{2}$ \\ ${ }^{1}$ Department of Molecular and Cell Biology, University of California Berkeley, Berkeley, CA 94720, USA; \\ ${ }^{2}$ Shanghai Licheng Bio-Technique Co. Ltd.; ${ }^{3}$ Shanghai Yiai Biomedical Technology Co. Ltd., Shanghai 201900, P.R. China
}

Received December 2, 2020; Accepted April 13, 2021

DOI: 10.3892/ijmm.2021.5070

\begin{abstract}
Stroke is the leading cause of disabilities and cognitive deficits, accounting for $5.2 \%$ of all mortalities worldwide. Transient or permanent occlusion of cerebral vessels leads to ischemic strokes, which constitutes the majority of strokes. Ischemic strokes induce brain infarcts, along with cerebral tissue death and focal neuronal damage. The infarct size and neurological severity after ischemic stroke episodes depends on the time period since occurrence, the severity of ischemia, systemic blood pressure, vein systems and location of infarcts, amongst others. Ischemic stroke is a complex disease, and neuronal injuries after ischemic strokes have been the focus of current studies. The present review will provide a basic pathological background of ischemic stroke and cerebral infarcts. Moreover, the major mechanisms underlying ischemic stroke and neuronal injuries are summarized. This review will also briefly summarize some representative clinical trials and up-to-date treatments that have been applied to stroke and brain infarcts.
\end{abstract}

\section{Contents}

1. Introduction

2. Pathophysiological processes of ischemia

3. Clinical management

4. Conclusion and future perspectives

Correspondence to: Dr Xinye Chen, Shanghai Licheng Bio-Technique Co. Ltd., Lane 2999, Hutai Road, Baoshan, Shanghai 201900, P.R. China E-mail: xinyechen00@163.com

*Contributed equally

Abbreviations: AIS, acute ischemic stroke; MCAO, middle cerebral artery occlusion; BBB, blood brain barrier; NPC, neural precursor cell; NMDARs, N-methyl-D-aspartate receptors; WRAP53, WD repeat containing antisense to TP53; GluN2B, NMDA Receptor 2B; NSCs, neural stem cells; PB, Persian blue; ROS, reactive oxygen species; HPBZs, hollow Prussian blue nanozymes; tMCAO, temporary MCAO; FDA, Food and Drug Administration

Key words: cerebral infarcts, ischemic stroke, neuronal injury, mechanism, clinical management

\section{Introduction}

Stroke was the leading cause of disabilities and cognitive deficits, and the fifth leading cause of mortality in the USA in 2017 (1). Moreover, ischemic stroke accounted for $5.2 \%$ of all deaths worldwide in 2015 (2). The basic pathological cause of ischemic stroke is intravascular thrombosis, which can result in cerebral tissue necrosis and focal neuronal deficits. There are three known leading causes of ischemic strokes: $50 \%$ are caused by arteriosclerotic plaques of the cerebral vessels and the rupture of the arteriosclerotic plaque, $20 \%$ are caused by cardiogenic cerebral infarction, and $25 \%$ are caused by Lacunar infarcts from small vessel lesions (3). Furthermore, the remaining $5 \%$ are due to other exceptional cause such as vasculitis and extracranial arterial dissection (4).

Acute ischemic stroke (AIS) is a type of ischemic stroke that can cause severe brain and neuronal damage in a very short time after the ischemic episode (5). Various degrees and types of brain damage are caused by ischemic stroke and cerebral infarcts, including cerebral tissue lesions and structural damage, and neuronal death and deficits, amongst others. Clinical symptoms of these types of damage can be observed in patients with conditions such as Alzheimer's disease (6-11), motor functional deficits (12), impaired intelligence quotient score (13) and multiple cognitive functional deficits (selective attention, working memory, information processing, abstract reasoning and verbal comprehension), amongst others (14-19). According to the findings of numerous studies examining the mechanisms and clinical management of ischemic stroke and cerebral infarction, there are three major mechanisms underlying the neuronal injuries caused by ischemic stroke and cerebral infarcts. Firstly, the loss of neurons induced by ischemia and infarcts is one of the most direct cause of neuronal injuries (20). With regards to this mechanism, researchers have been focusing on the processes of neuroprotection and regeneration, as well as related biomarkers and molecular pathways (20). Secondly, vascular obstruction caused by ischemia excessively produces reactive oxygen species (ROS), and it has been shown that oxidative stress exacerbates neuronal damage and leads to severe functional deficits (21). Pathways reacting to and relieving oxidative stress are widely investigated to help decrease neuronal injuries. Inflammation induced by ischemia is an additional factor that leads to further neuronal damage after 
strokes (22). Therefore, effectively manipulating the immune responses may help to reduce neuronal injuries.

In vivo animal models of ischemic stroke and brain infarcts provide valuable insights into the underlying mechanisms and possible clinical therapies. The middle cerebral artery occlusion (MCAO) model in murine models is most widely used for in vivo studies (23). Embolic MCAO models closely mimic human stroke, $>80 \%$ of which are caused by thrombosis or embolism (24). MCAO produces regenerative occlusion in middle cerebral arteries, and also enables reperfusion without extracranial resection of the occlusion (25). Although the mechanism of such rapid recovery of blood flow differs from the pathophysiology of human strokes, this model can still commendably simulate the clinical application of mechanical thrombolysis (25), which may be more widely applied in patients in the future. In addition, the various models of embolic stroke and spontaneous stroke can most effectively simulate the real condition of human strokes $(26,27)$. Different experimental models have contributed significantly to the current knowledge regarding stroke pathophysiology and its consequences, and each model causes different changes in the cerebral microcirculation and local inflammatory responses after ischemia (26). Nevertheless, these models are accompanied by higher instability regarding the size and location of infarcts. For instance, such instability includes unpredictable stroke attacks in spontaneous stroke models and unpredictable reperfusion conditions in embolic stroke models (23).

The ultimate therapeutic goal for ischemic stroke and brain infarcts is to reduce neuronal injuries by relieving arterial occlusion (recanalization) and recovering cerebral blood flow (reperfusion) (28). The basic hypothesis of the pathophysiological response during AIS treatment is that once the cerebral artery has been occluded, hypo-perfused brain tissues are at risk of permanent infarction, but such tissues can be effectively rescued via the rapid recovery of the blood flow (29). These tissues are known as ischemic penumbras, and preventing the conversion of ischemic penumbra to inversible infarction is the aim of AIS treatment (28). Primary stroke treatment challenges are partly a result of distinguishing the penumbra from the core zone and the penumbra from benign hypoperfusion tissues, which have poor perfusion but without the risk of infarction (30).

\section{Pathophysiological processes of ischemia}

Investigations into ischemic stroke and neuronal injuries have indicated that neuronal damage is caused by neuron loss, oxidative stress and immune responses (31-33). Various biomarkers and molecular pathways are involved in rescuing neuronal damage caused by ischemic stroke and cerebral infarction.

Neuron protection and regeneration. The survival of neurons influences the stability and completeness of brain functions, and neuron loss directly results in cerebral functional deficits (34). Hence, neuronal protection and regeneration has been the major focus for effectively rescuing cerebral functional deficits. There are various methods to achieve this goal, which include enhancing neuron protection, promoting neuron repair and neuron regeneration, and direct mediation of neuronal survival or death, amongst others. For instance, astrocytes contribute to angiogenesis, neurogenesis, synaptogenesis and axonal remodeling (35). Thus, promoting neurological recovery during the late recovery phase after stroke could provide benefits for neuroprotection. Astrocytes limit lesion extension by exerting anti-excitotoxicity effects and releasing neurotrophins (36). Therefore, the pivotal involvement of astrocyte responses to an ischemic lesion designates them as excellent therapeutic targets to improve the functional outcome following stroke. In addition, the blockade of the GSK-3 $\beta$-induced degradation of $\beta$-catenin, which in turn promotes neuronal survival, represents a key step in the ability of Wnt1 to safeguard midbrain dopaminergic neurons (37). Within the central nervous system, Wnt signaling cascades orchestrate all aspects of neuronal functions, including differentiation, neuron death or survival, axonal extension, synapse formation and plasticity, neurotrophin transcription, neurogenesis and regeneration (38-41).

Voltage-gated $K^{+}$channel $(K v) 2.1 / K v 2.2$ pathway and neuron protection. Kv2.1 is involved in the neuron apoptosis pathway. Neurons characterized with low functional expression of Kv2.1 are observed to have high resistance against apoptotic stimuli (42). However, overexpression of the $C$ terminal in its homologous Kv2.2 pathway interferes with the Kv2.1 cluster, without affecting other active channels. Such interference leads to neuron protection by blocking the increased current intensity of the $\mathrm{K}^{+}$pathway $(43,44)$. In a previous study, it was identified that a seven-amino acid declustering domain, SIDSFTS, induces the dispersion of the Kv2.1 cluster to protect neurons in a murine ischemia-reperfusion model (45). Furthermore, the membrane-permeable derivative, TAT-DP-2, induces Kv2.1 surface cluster dispersal, prevents post-injurious pro-apoptotic potassium current intensity enhancement, reduces infarct size and improves long-term neurological function following stroke (45). The therapeutic peptide derived from TAT-DP-2 is permeable to the blood brain barrier (BBB), providing effective neuron protection in murine models after ischemic stroke in vivo (45). Thus, destruction of the Kv2.1 cluster provides neuronal protection (Fig. 1) (45).

WD repeat containing antisense RNA targeting TP53 (WRAP53) mediates neuron repair. It has been shown that WRAP53 expression induces DNA double strand repair in neurons to promote functional recovery after ischemic stroke (46). Moreover, oxygen/glucose deprivation induces excessive production of ROS in murine stroke models, and ROS break DNA double strands in neurons (47). Furthermore, WRAP53 activation promotes DNA repair after its translocation into the nucleus. Knockdown of WRAP53 exacerbates DNA double strand damage, which results in lower resistance to apoptotic stimuli in neurons. By contrast, overexpression of WRAP53 activates DNA double strand repair, and consequently promotes neuron protection and survival (46). Clinical trials have demonstrated that high WRAP53, a telomere-related gene, may be beneficial for healthspan in humans, reversing certain deleterious metabolic consequences of prediabetes (48).

Neural precursor cells (NPCs) mediate astrocyte-neuron conversion. NPCs facilitate the survival, proliferation and 


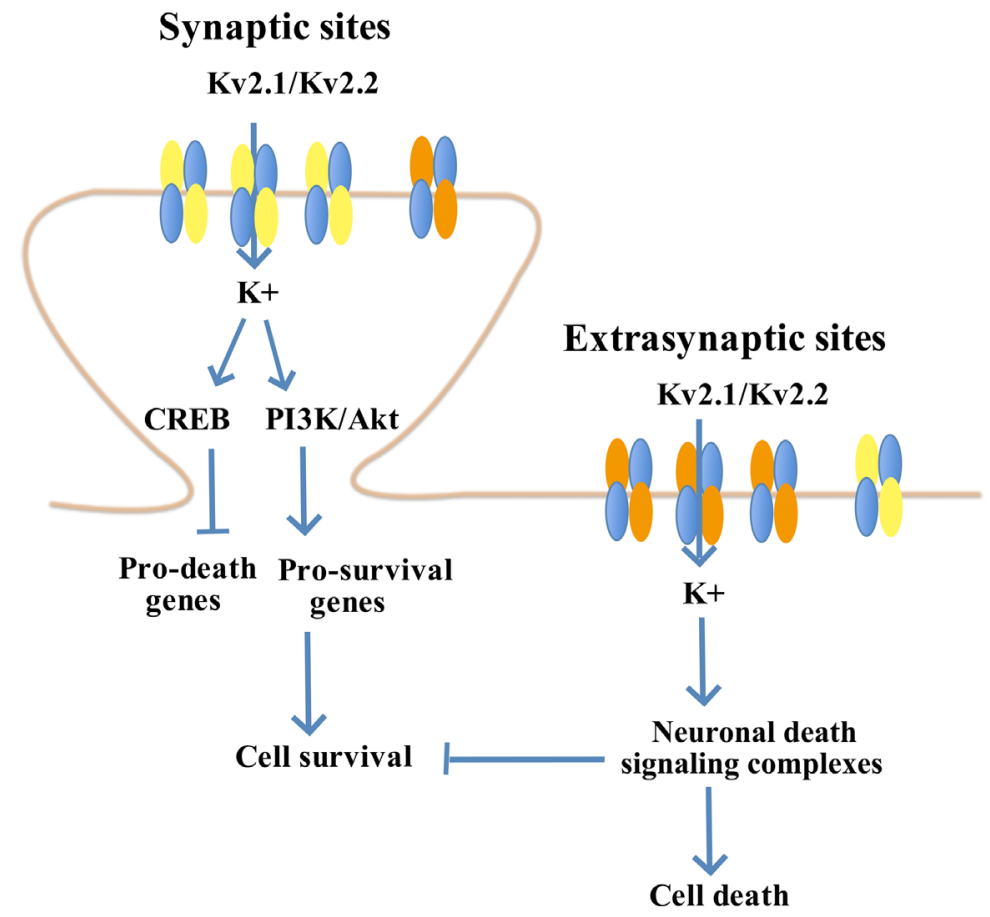

Figure 1. Kv2.1/Kv2.2 pathway in neuron protection. Kv, voltage-gated $\mathrm{K}^{+}$channel. CREB, Cyclic AMP response-element binding protein; PI3K/Akt, phosphatidylinositol-4,5-bisphosphate 3-kinase/protein kinase B.

regeneration of neurons in stroke areas and infarct zones in animal models (9-11). Some clinical trials have reported positive results for the use of NPCs in patients (49). Moreover, transplantation of external NPCs is another potential clinical treatment for strokes (6-8). Neurotrophic factors are used to amplify neuron regeneration in adult mammalian brains via embedded neurogenesis, but this only contributes to $<1 \%$ of the neuron loss caused by ischemic strokes (50-54).

Having been transplanted into damaged cortical zones, neural stem cells (NSCs) from the cerebral pituitary chamber are responsible for producing astrocytes rather than neurons $(55,56)$. Furthermore, transplanted external NSCs are associated with various challenges, such as immunological rejection, tumor progression and poor long-term survival (12,49,57-59). In addition, astrocytes can be converted to neurons after ischemic stroke in vitro and in vivo (13-17,19,60-62). For instance, Chen et al (20) reported a $74.3 \%$ astrocyte-neuron conversion rate in murine models after stroke. However, the clinical effects of this conversion in patients has not been investigated.

$N$-methyl-D-aspartate receptor (NMDAR) bidirectional regulation of neuronal survival or death. NMDARs are a crucial regulatory factor of neuron injuries and ischemic stroke. NMDARs serve a double-edged role in the regulation of neuronal survival or death (63-65). Firstly, different subtypes of NMDARs regulate neuronal survival and death (66-68). It has shown that NMDAR antagonists, containing NMDA receptor $2 \mathrm{~B}$ (GluN2B), relieve the toxicity caused by NMDA in temporary MCAO (tMCAO) models in vitro and in vivo. However, NMDAR antagonists containing GluN2A aggravate neuronal death rather than relieving its effects $(66,68-74)$. Secondly, the functions of NMDARs vary with their locations. Indeed, NMDARs inside and outside the synapse exert opposite functions $(63,75,76)$. NMDAR downstream mechanisms and pathways are complex (77-81). NMDARs inside and outside of synapses evoke ERK1/2 kinases, but only the NMDARs inside the synapse increase the level of ERK phosphorylation to provide protection for neurons under toxic conditions $(80,82)$. Notably, stimulation of the NMDAR outside the synapse inactivates ERK1/2 (82). Thirdly, NMDARs serve various roles in signaling pathways that modulate neuronal survival and death $(64,65)$. A low concentration of NMDA activates NSCs to exert a neuroprotective response. Furthermore, the PI3K/Akt kinase and MAPK pathways are downstream of NMDARs involved in neuron survival (Fig. 2) $(63,83)$. MAPK signaling pathway members, including p44/42 MAPK (ERK1/2), JNK and p38 MAPK, regulate cell proliferation and differentiation, and the responses to cytokines and stress during protein kinase cascades. However, NMDARs induce neural toxicity by activating NSCs, in the form of the GluN2B-postsynaptic density protein 95-neuronal nitric oxides synthase complex $(84,85)$, GluN2B-death associated protein kinase 1-p53 complex $(86,87)$ or GluN1-PTEN complex (88) (Fig. 3).

Oxidative stress. Heme oxygenase 1 (HO-1) is highly expressed in brain tissues after cerebral injuries, including stroke and infarction, and a high expression level of HO-1 symbolizes the activation of the protective mechanism against oxidative stress (89). Brain injuries are associated with oxidative stress. It has been revealed that Persian blue (PB) nanoparticles effectively eliminate excessive ROS produced by ischemic stroke and cerebral infarcts. PB exerts a similar function to catalase, superoxide dismutase and peroxidase $(90,91)$. Moreover, hollow Prussian blue nanozymes (HPBZs) react and neutralize inflammation caused by immune responses, as well as suppressing neuron apoptosis in vitro and in vivo. Thus, 


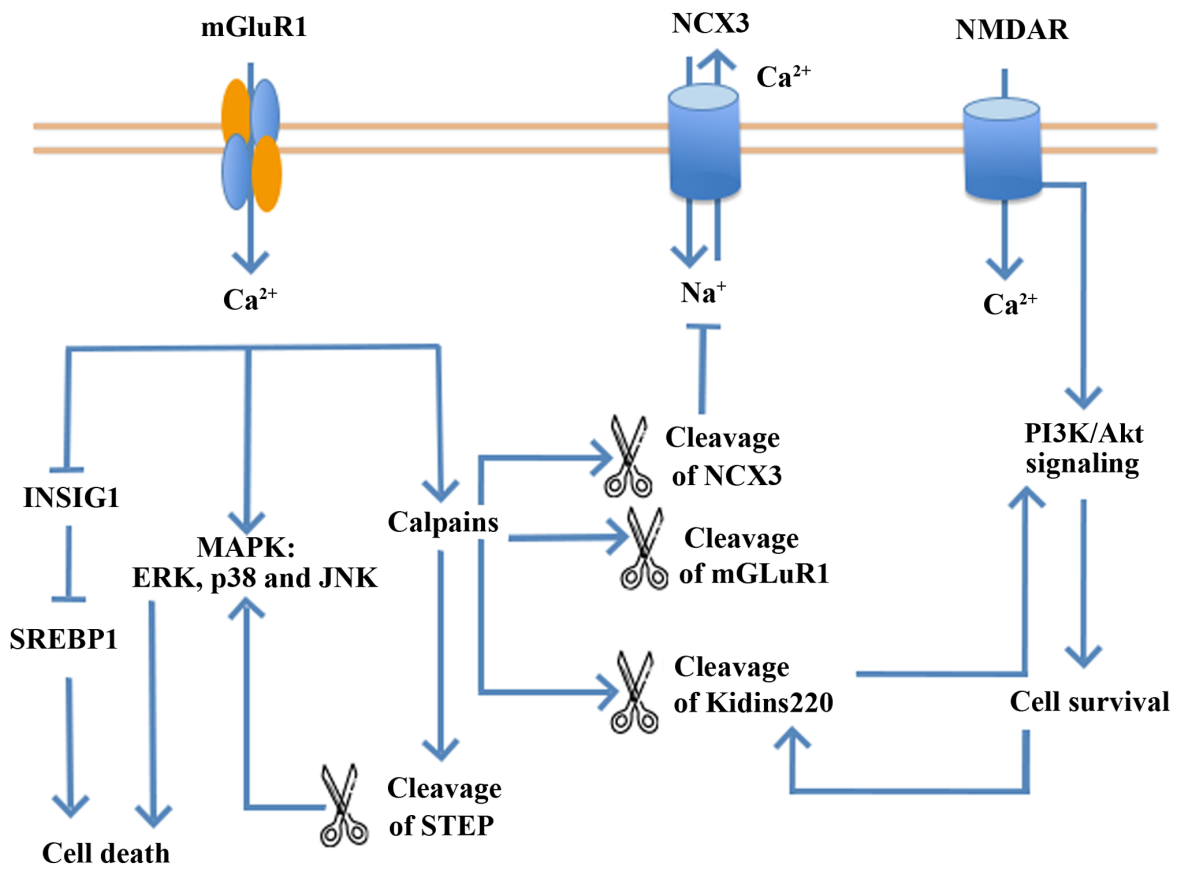

Figure 2. NMDARs mediate bidirectional regulation of neuronal survival or death. NMDAR, N-methyl-D-aspartate receptor; mGluR1, metabotropic glutamate receptor subtype 1; INSIG1, insulin-induced gene 1; SREBP1, sterol regulatory element binding protein 1; STEP, striatal-enriched protein tyrosine phosphatase; ERK, extracellular signal-regulated kinase; MAPK, mitogen-activated protein kinase; JNK, c-Jun N-terminal kinase; NCX3, sodium-calcium exchanger 3.

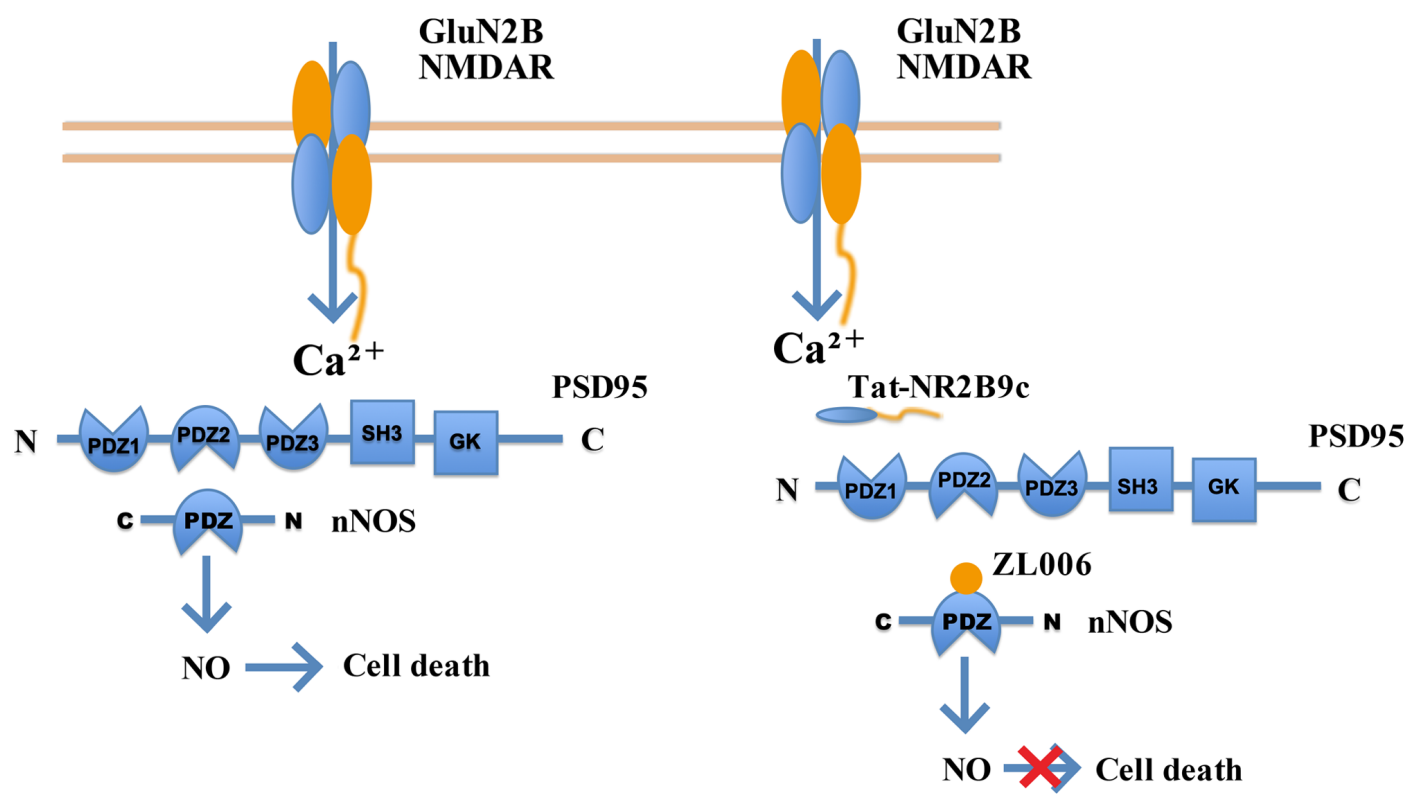

Figure 3. NMDARs induce neural toxicity through the GluN2B-postsynaptic density protein 95-nNOS axis. NMDAR, N-methyl-D-aspartate receptor; GluN2B, NMDAR receptor 2B; nNOS, neuronal nitric oxides synthase; PDZ, PSD95 discs-large and zona occludens-1; Tat-NR2B9c, postsynaptic density 95 blocking peptide; ZL006, a small-molecular inhibitor of the nNOS-PSD-95 interaction; SH3, Src Homology 3; GK, guanylate kinase.

HPBZs increase the tolerance to strokes and minimize neural injuries (92).

Immune responses. Stroke interrupts the blood flow into the brain. The pathophysiology of stroke involves a progressive systematic response after brain damage (93). Animal stroke models (94) and clinical patients (95) show dynamic BBB rupture. The BBB fracture induced by stroke initiates a series of pathological responses. The hyperinflammatory responses caused by strokes include increased levels of inflammatory cells, cytokines and chemokines in the circulating blood (96). Recently, it has been shown that infarct sizes are effectively decreased and that a promising recovery of neural injuries occurs at 6.5-7 $\mathrm{h}$ after the stroke in an animal model of tMCAO (22). The intervention used in this model was blood substitution therapy to replace the blood of mice suffering from strokes with the whole blood from healthy infant mice (22). The possible underlying mechanisms in this therapy may be as follows: Firstly, the brain antigens released after the rupture of the BBB may activate the immune system after stroke. 
Therefore, replacing the blood in mice with strokes may reduce the amount of brain antigens in the circulating blood to alleviate the immune responses after stroke. Secondly, replacing the blood in mice with strokes effectively reduces the number of activated leukocytes. Thus, large amounts of harmful signals in circulating blood after stroke, including cytokines, chemokines and proteases, are decreased. Finally, new replacement blood may provide oxygen and various other neuroprotective factors.

Platelet microvesicle (PMV) intervention and microRNAs (miRNAs/miRs). The molecular mechanism of neuronal damage caused by ischemic stroke and cerebral infarction is complex. In addition to the molecular processes previously mentioned, multiple other factors also provide new insights into the treatment of stroke. Recently, PMVs have been found to significantly improve the recovery of neurological function in mice with cerebral infarction and promote angiogenesis at the infarction edge (97). The procoagulant and proinflammatory phenotype of circulating PMVs may contribute to acetylsalicylic acid treatment failure in patients with convalescent stroke (98).

Accumulating evidence has shown that exosomal miRNAs are one of the most important factors involved in the pathogenesis of stroke. Exosomal miRNAs are used as non-invasive biomarkers in stroke diagnosis and for monitoring the response during therapy (99). Antagomirs (anti-miRNAs) are an effective treatment method to enhance neuronal survival in various animal models, for example, administration of an antisense oligonucleotide inhibitor of miR-129-5p to an amyotrophic lateral sclerosis animal model, SOD1 (G93A) mice, resulted in a significant increase in survival and improved the neuromuscular phenotype in treated mice (100); and some miRNAs show therapeutic effects in stroke (101). These miRNAs affect the pathways induced by stroke, including leukocyte extravasation signaling, NF- $\mathrm{B}$ signaling, Toll-like receptor signaling and the prothrombin activation pathway (102). For instance, miR-122, miR-9, miR-298 and miR-155-5p participate in brain injury after stroke by targeting different genes involved in the NF- $\kappa \mathrm{B}$ signaling pathway (103-106). Thus, miRNAs are crucial in stroke progression, diagnosis, therapy and prognosis.

\section{Clinical management}

At present, thrombolytic therapy is the most widely applied treatment for ischemic stroke and brain infarction (107). The basic principle of thrombolysis is to recanalize and reperfuse cerebral arteries using thrombolytic drugs and mechanical thrombectomy devices, eventually leading to the partial recovery of brain tissues and neural functions (108). The clinical effectiveness of intravenous thrombolytic therapy has been established for patients within $4.5 \mathrm{~h}$ of stroke onset. However, numerous patients experience complicated situations, such as proximal artery occlusion, $>4.5 \mathrm{~h}$ of stroke onset and contraindication of systemic thrombolysis due to recent major surgeries or active hemorrhage. Such patients are not suitable for intravenous thrombolysis therapy (109). Therefore, a recent review indicated that several studies and clinical trials have focused on catheter or artery-based treatments that directly remove occlusions in blood vessels and recover the blood flow (28).
Intravenous thrombolysis. Clinical trials funded by the United States Natural Institute of Neurological Diseases and Stroke and the European Acute Stroke Study have shown that intravenous thrombolysis has strong effects in patients with mild symptoms or no disability, and that intravenous thrombolysis has more benefits than limitations in patients with a full range of disabilities $(110,111)$. For instance, treatment with tissue plasminogen activator in the 3 - to 4.5 -h window confers benefit on approximately half as many patients as treatment for $<3 \mathrm{~h}$, with no increase in the conferral of harm; $\sim 1$ in 6 patients has a better outcome and 1 in 35 has a worse outcome as a result of therapy. Previous studies (112-114) have established intravenous thrombolysis as the standard therapy for patients with AIS within $3 \mathrm{~h}$ of stroke onset. Intravenous thrombolysis is beneficial for all levels and subtypes of strokes (115), and 35-40\% of patients displayed a good therapeutic outcome. However, only $10-15 \%$ of internal carotid artery occlusions and $25-50 \%$ of proximal MCAO were alleviated by intravenous thrombolysis therapy alone. These data indicated that the proximal artery occlusion (internal carotid artery and MCAO) may be resistant to intravenous thrombolysis therapy alone $(116,117)$. Proximal artery occlusion leads to one-third of AIS cases with severe stroke symptoms and has the negative outcome of ineffective reperfusion (118). Thus, several large-scale clinical trials have been focusing on identifying other substitutional or adjunctive therapies based on intravenous thrombolysis to improve recanalization and the reperfusion rate.

Arterial thrombolysis. Arterial thrombolysis consists of chemical thrombolysis and mechanical thrombectomy, and the use of intravenous therapy prior to mechanical thrombectomy has been recently questioned (118). The clinical efficacy and safety of arterial thrombolysis with the selective thrombolytic recombinant-pro-urokinse (r-proUK) has been investigated in two randomized acute stroke treatment trials, namely PROACT I and PROACT II (119). It has been shown that patients treated with such therapy experience the risk of cerebral hemorrhage. Moreover, the outcome of combining arterial thrombolysis with other agents as therapy remains unclear. Therefore, the Food and Drug Administration (FDA) did not grant the clinical application of arterial r-proUK. Nevertheless, a recent study reported that r-proUK promoted thrombolysis and recanalization, with a decreased risk of cerebral hemorrhage, and thus, this treatment exerted protective effects on cerebral ischemia in rabbits (120).

Different from recently developed chemical thrombolysis, mechanical thrombectomy has been widely applied in the clinic (121). The FDA granted permission of several mechanical thrombectomy devices based on positive results yielded by numerous large-scale clinical trials (122). These devices can effectively recanalize proximal artery occlusion with an acceptable rate of complications $(123,124)$. Indeed, any type of intracerebral hemorrhage was observed less frequently in the mechanical thrombectomy alone group compared with that in the group using the combination of intravenous thrombolysis with mechanical thrombectomy (125). However, the mechanical thrombectomy alone group failed to show a favorable functional outcome among patients with acute large vessel occlusion stroke compared with the combined group. Furthermore, a recent finding supported the hypothesis that 
intravenous therapy before mechanical thrombectomy does not influence the prognosis of patients with stroke (126).

Pre-clinical magnetic resonance imaging. Trials of novel recanalization methods based on MRI tool selection of patients are ongoing. Unless a specific lesion site is taken into account, functional deficits due to medium-sized infarcts are difficult to predict (127). Accurate information regarding the location of the lesion and the progression of the disease is crucial for clinic therapy. Therefore, promising neuroprotective compounds in the pre-clinical phase can be subsequently dismissed for ineffectiveness in large-scale clinical trials due to inaccurate information. Infarction of the internal capsule (IC) may be associated with motor impairment and poor prognosis in patients with stroke (128). Pre-clinical MRI information regarding volume size and the precise location of the lesion into the IC is required for subsequent therapy. Moreover, the state of neurological damage according to MRI, as well as the destruction of axonal structures and pathological changes according to immunostaining, provide information for the precise injection site of neuroprotective drugs (129). Thus, combined MRI and histological methods provide a powerful method of assessing neuronal damage during cerebral ischemia therapy (129).

\section{Conclusion and future perspectives}

Ischemic stroke leads to severe outcomes, including cerebral infarcts, permanent brain damage and neural functional deficits. Therefore, decreasing and preventing neural injuries caused by stroke and infarctions has been the focus of mechanistic and therapeutic studies. The current review summarized the pathophysiology, molecular mechanisms, animal models, and clinical management and therapies in ischemic strokes. The related molecular mechanisms in clinical trials should be further investigated. The American Heart Association has suggested that arterial thrombolysis is an acceptable alternative therapy for strokes. Multiple stroke centers provide arterial thrombolysis for patients experiencing a major acute stroke attack within $6 \mathrm{~h}$. However, the molecular mechanism underlying arterial thrombolysis remains to be fully investigated.

\section{Acknowledgements}

Not applicable.

\section{Funding}

No funding was received.

\section{Availability of data and materials}

Not applicable.

\section{Authors' contributions}

$\mathrm{YZ}$ and $\mathrm{XZ}$ wrote the manuscript. $\mathrm{YZ}, \mathrm{XZ}, \mathrm{YW}$ and $\mathrm{XC}$ searched the relevant literature. $\mathrm{XC}$ and $\mathrm{YW}$ critically reviewed the manuscript. All authors have read and approved the final version of the manuscript. Data authentication is not applicable.

\section{Ethics approval and consent to participate}

Not applicable.

\section{Patient consent for publication}

Not applicable.

\section{Competing interests}

The authors declare that they have no competing interests.

\section{References}

1. Benjamin EJ, Blaha MJ, Chiuve SE, Cushman M, Das SR, Deo R, de Ferranti SD, Floyd J, Fornage M, Gillespie C, et al: Heart disease and stroke statistics-2017 update: A report from the American Heart Association. Circulation 135: e146-e603, 2017.

2. GBD 2015 Mortality and Causes of Death Collaborators: Global, regional, and national life expectancy, all-cause mortality, and cause-specific mortality for 249 causes of death, 1980-2015: A systematic analysis for the Global Burden of Disease Study 2015. Lancet 388: 1459-1544, 2016.

3. Bailey EL, Smith C, Sudlow CL and Wardlaw JM: Pathology of lacunar ischemic stroke in humans-a systematic review. Brain Pathol 22: 583-591, 2012.

4. Warlow C, Sudlow C, Dennis M, Wardlaw J and Sandercock P: Stroke. Lancet 362: 1211-1224, 2003.

5. Balch MHH, Nimjee SM, Rink C and Hannawi Y: Beyond the brain: The systemic pathophysiological response to acute ischemic stroke. J Stroke 22: 159-172, 2020.

6. Boyle PA, Yang J, Yu L, Leurgans SE, Capuano AW, Schneider JA, Wilson RS and Bennett DA: Varied effects of age-related neuropathologies on the trajectory of late life cognitive decline. Brain 140: 804-812, 2017.

7. Boyle PA, Yu L, Wilson RS, Schneider JA and Bennett DA: Relation of neuropathology with cognitive decline among older persons without dementia. Front Aging Neurosci 5: 50, 2013.

8. Corrada MM, Sonnen JA, Kim RC and Kawas CH: Microinfarcts are common and strongly related to dementia in the oldest-old: The 90+ study. Alzheimers Dement 12: 900-908, 2016.

9. Ince PG, Minett T, Forster G, Brayne C, Wharton SB, Medical Research Council Cognitive Function and Ageing Neuropathology Study: Microinfarcts in an older population-representative brain donor cohort (MRC CFAS): Prevalence, relation to dementia and mobility, and implications for the evaluation of cerebral Small Vessel Disease. Neuropathol Appl Neurobiol 43: 409-418, 2017.

10. Kawas CH, Kim RC, Sonnen JA, Bullain SS, Trieu T and Corrada MM: Multiple pathologies are common and related to dementia in the oldest-old: The 90+ study. Neurology 85: 535-542, 2015.

11. White LR, Edland SD, Hemmy LS, Montine KS, Zarow C, Sonnen JA, Uyehara-Lock JH, Gelber RP, Ross GW, Petrovitch H, et al: Neuropathologic comorbidity and cognitive impairment in the Nun and Honolulu-Asia aging studies. Neurology 86: 1000-1008, 2016

12. Buchman AS, Yu L, Boyle PA, Levine SR, Nag S, Schneider JA and Bennett DA: Microvascular brain pathology and late-life motor impairment. Neurology 80: 712-718, 2013.

13. Hogan AM, Kirkham FJ, Prengler M, Telfer P, Lane R, Vargha-Khadem F and Haan M: An exploratory study of physiological correlates of neurodevelopmental delay in infants with sickle cell anaemia. Br J Haematol 132: 99-107, 2006.

14. Bernaudin F, Verlhac S, Freard F, Roudot-Thoraval F, Benkerrou M, Thuret I, Mardini R, Vannier JP, Ploix E, Romero M, et al: Multicenter prospective study of children with sickle cell disease: Radiographic and psychometric correlation. J Child Neurol 15: 333-343, 2000.

15. Brown RT, Davis PC, Lambert R, Hsu L, Hopkins K and Eckman J: Neurocognitive functioning and magnetic resonance imaging in children with sickle cell disease. J Pediatr Psychol 25: 503-513, 2000

16. DeBaun MR, Schatz J, Siegel MJ, Koby M, Craft S, Resar L, Chu JY, Launius G, Dadash-Zadeh M, Lee RB and Noetzel M: Cognitive screening examinations for silent cerebral infarcts in sickle cell disease. Neurology 50: 1678-1682, 1998. 
17. Hogan AM, Pit-ten Cate IM, Vargha-Khadem F, Prengler M and Kirkham FJ: Physiological correlates of intellectual function in children with sickle cell disease: Hypoxaemia, hyperaemia and brain infarction. Dev Sci 9: 379-387, 2006.

18. Steen RG, Miles MA, Helton KJ, Strawn S, Wang W, Xiong X and Mulhern RK: Cognitive impairment in children with hemoglobin SS sickle cell disease: Relationship to MR imaging findings and hematocrit. AJNR Am J Neuroradiol 24: 382-389, 2003.

19. Watkins KE, Hewes DK, Connelly A, Kendall BE, Kingsley DP, Evans JE, Gadian DG, Vargha-Khadem F and Kirkham FJ: Cognitive deficits associated with frontal-lobe infarction in children with sickle cell disease. Dev Med Child Neurol 40: 536-543, 1998.

20. Chen YC, Ma NX, Pei ZF, Wu Z, Do-Monte FH, Keefe S, Yellin E, Chen MS, Yin JC, Lee G, et al: A neuroD1 AAV-based gene therapy for functional brain repair after ischemic injury through in vivo astrocyte-to-neuron conversion. Mol Ther 28: 217-234, 2020

21. Hu X, Wu D, He X, Zhao H, He Z, Lin J, Wang K, Wang W, Pan Z, Lin $\mathrm{H}$ and Wang $\mathrm{M}$ : circGSK $3 \beta$ promotes metastasis in esophageal squamous cell carcinoma by augmenting $\beta$-catenin signaling. Mol Cancer 18: 160, 2019.

22. Ren X, Hu H, Farooqi I and Simpkins JW: Blood substitution therapy rescues the brain of mice from ischemic damage. Nat Commun 11: 4078, 2020.

23. Sommer CJ: Ischemic stroke: Experimental models and reality. Acta Neuropathol 133: 245-261, 2017.

24. Zhang L, Zhang RL, Jiang Q, Ding G, Chopp M and Zhang ZG: Focal embolic cerebral ischemia in the rat. Nat Protoc 10 539-547, 2015.

25. McBride DW and Zhang JH: Precision stroke animal models: The permanent MCAO model should be the primary model, not transient MCAO. Transl Stroke Res: Jul 17, 2017 (Epub ahead of print). doi: 10.1007/s12975-017-0554-2.

26. Lunardi Baccetto S and Lehmann C: Microcirculatory changes in experimental models of stroke and CNS-injury induced immunodepression. Int J Mol Sci 20: 5184, 2019.

27. Fujie W, Kirino T, Tomukai N, Iwasawa $T$ and Tamura $A$ : Progressive shrinkage of the thalamus following middle cerebra artery occlusion in rats. Stroke 21: 1485-1488, 1990.

28. Prabhakaran S, Ruff I and Bernstein RA: Acute stroke intervention: A systematic review. JAMA 313: 1451-1462, 2015.

29. Zhao Y, Yuan B, Chen J, Feng D, Zhao B, Qin C and Chen YF: Endothelial progenitor cells: Therapeutic perspective for ischemic stroke. CNS Neurosci Ther 19: 67-75, 2013.

30. Kidwell CS, Alger JR and Saver JL: Beyond mismatch: Evolving paradigms in imaging the ischemic penumbra with multimodal magnetic resonance imaging. Stroke 34: 2729-2735, 2003.

31. Khoshnam SE, Winlow W, Farzaneh M, Farbood Y and Moghaddam HF: Pathogenic mechanisms following ischemic stroke. Neurol Sci 38: 1167-1186, 2017.

32. Guo JD, Zhao X, Li Y, Li GR and Liu XL: Damage to dopaminergic neurons by oxidative stress in Parkinson's disease (Review). Int J Mol Med 41: 1817-1825, 2018.

33. Kierdorf K, Wang Y and Neumann H: Immune-mediated CNS damage. Results Probl Cell Differ 51: 173-196, 2010.

34. Lazarov $\mathrm{O}$ and Hollands C: Hippocampal neurogenesis: Learning to remember. Prog Neurobiol 138-140: 1-18, 2016.

35. Sun L, Zhang Y, Liu E, Ma Q, Anatol M, Han H and Yan J: The roles of astrocyte in the brain pathologies following ischemic stroke. Brain Inj 33: 712-716, 2019.

36. Liu Z and Chopp M: Astrocytes, therapeutic targets for neuroprotection and neurorestoration in ischemic stroke. Prog Neurobiol 144: 103-120, 2016.

37. L'Episcopo F, Serapide MF, Tirolo C, Testa N, Caniglia S, Morale MC, Pluchino S and Marchetti B: A Wnt1 regulated Frizzled-1/ $\beta$-Catenin signaling pathway as a candidate regulatory circuit controlling mesencephalic dopaminergic neuron-astrocyte crosstalk: Therapeutical relevance for neuron survival and neuroprotection. Mol Neurodegener 6: 49, 2011.

38. Salinas PC: Wnt signaling in the vertebrate central nervous system: From axon guidance to synaptic function. Cold Spring Harb Perspect Biol 4: a008003, 2012.

39. Grainger S and Willert K: Mechanisms of Wnt signaling and control. Wiley Interdiscip Rev Syst Biol Med: Mar 30, 2018 (Epub ahead of print). doi: 10.1002/wsbm.1422.

40. Kalani MY, Cheshier SH, Cord BJ, Bababeygy SR, Vogel H, Weissman IL, Palmer TD and Nusse R: Wnt-mediated self-renewal of neural stem/progenitor cells. Proc Natl Acad Sci USA 105: 16970-16975, 2008.
41. Clevers H, Loh KM and Nusse R: Stem cell signaling. An integral program for tissue renewal and regeneration: Wnt signaling and stem cell control. Science 346: 1248012, 2014

42. Pal S, Hartnett KA, Nerbonne JM, Levitan ES and Aizenman E Mediation of neuronal apoptosis by Kv2.1-encoded potassium channels. J Neurosci 23: 4798-4802, 2003.

43. Baver SB and O'Connell KM: The C-terminus of neuronal Kv2.1 channels is required for channel localization and targeting but not for NMDA-receptor-mediated regulation of channel function. Neuroscience 217: 56-66, 2012.

44. Justice JA, Schulien AJ, He K, Hartnett KA, Aizenman E and Shah NH: Disruption of KV2.1 somato-dendritic clusters prevents the apoptogenic increase of potassium currents. Neuroscience 354: 158-167, 2017.

45. Schulien AJ, Yeh CY, Orange BN, Pav OJ, Hopkins MP, Moutal A, Khanna R, Sun D, Justice JA and Aizenman E: Targeted disruption of Kv2.1-VAPA association provides neuroprotection against ischemic stroke in mice by declustering Kv2.1 channels. Sci Adv 6: eaaz8110, 2020.

46. Sánchez-Morán I, Rodríguez C, Lapresa R, Agulla J, Sobrino T, Castillo J, Bolaños JP and Almeida A: Nuclear WRAP53 promotes neuronal survival and functional recovery after stroke. Sci Adv 6: eabc5702, 2020.

47. Ji HJ, Wang DM, Hu JF, Sun MN, Li G, Li ZP, Wu DH, Liu G and Chen NH: IMM-H004, a novel courmarin derivative, protects against oxygen-and glucose-deprivation/restoration-induced apoptosis in PC12 cells. Eur J Pharmacol 723: 259-266, 2014.

48. Canudas S, Hernández-Alonso P, Galié S, Muralidharan J, Morell-Azanza L, Zalba G, García-Gavilán J, Martí A, Salas-Salvadó J and Bulló M: Pistachio consumption modulates DNA oxidation and genes related to telomere maintenance: A crossover randomized clinical trial. Am J Clin Nutr 109: $1738-1745,2019$

49. van Rooden S, Goos JD, van Opstal AM, Versluis MJ, Webb AG, Blauw GJ, van der Flier WM, Scheltens P, Barkhof F, van Buchem MA and van der Grond J: Increased number of microinfarcts in Alzheimer disease at 7-T MR imaging. Radiology 270: 205-211, 2014.

50. Bernaudin F, Verlhac S, Arnaud C, Kamdem A, Chevret S, Hau I, Coïc L, Leveillé E, Lemarchand E, Lesprit E, et al: Impact of early transcranial Doppler screening and intensive therapy on cerebral vasculopathy outcome in a newborn sickle cell anemia cohort. Blood 117: 1130-1140, 2011.

51. Hindmarsh PC, Brozovic M, Brook CG and Davies SC: Incidence of overt and covert neurological damage in children with sickle cell disease. Postgrad Med J 63: 751-753, 1987.

52. Kwiatkowski JL, Zimmerman RA, Pollock AN, Seto W, Smith-Whitley K, Shults J, Blackwood-Chirchir A and Ohene-Frempong K: Silent infarcts in young children with sickle cell disease. Br J Haematol 146: 300-305, 2009.

53. Moser FG, Miller ST, Bello JA, Pegelow CH, Zimmerman RA, Wang WC, Ohene-Frempong K, Schwartz A, Vichinsky EP, Gallagher D and Kinney TR: The spectrum of brain MR abnormalities in sickle-cell disease: A report from the cooperative study of sickle cell disease. AJNR Am J Neuroradiol 17: 965-972, 1996.

54. Westover MB, Bianchi MT, Yang C, Schneider JA and Greenberg SM: Estimating cerebral microinfarct burden from autopsy samples. Neurology 80: 1365-1369, 2013.

55. Hilal S, Sikking E, Shaik MA, Chan QL, van Veluw SJ, Vrooman H, Cheng CY, Sabanayagam C, Cheung CY, Wong TY, et al: Cortical cerebral microinfarcts on 3T MRI: A novel marker of cerebrovascular disease. Neurology 87: 1583-1590, 2016.

56. van Veluw SJ, Hilal S, Kuijf HJ, Ikram MK, Xin X, Yeow TB, Venketasubramanian N, Biessels GJ and Chen C: Cortical microinfarcts on 3T MRI: Clinical correlates in memory-clinic patients. Alzheimers Dement 11: 1500-1509, 2015.

57. Anenberg E, Arstikaitis P, Niitsu Y, Harrison TC, Boyd JD, Hilton BJ, Tetzlaff W and Murphy TH: Ministrokes in channelrhodopsin-2 transgenic mice reveal widespread deficits in motor output despite maintenance of cortical neuronal excitability. J Neurosci 34: 1094-1104, 2014.

58. Summers PM, Hartmann DA, Hui ES, Nie X, Deardorff RL, McKinnon ET, Helpern JA, Jensen JH and Shih AY: Functional deficits induced by cortical microinfarcts. J Cereb Blood Flow Metab 37: 3599-3614, 2017.

59. Wang M, Iliff JJ,Liao Y, Chen MJ, Shinseki MS, Venkataraman A, Cheung J, Wang W and Nedergaard M: Cognitive deficits and delayed neuronal loss in a mouse model of multiple microinfarcts. J Neurosci 32: 17948-17960, 2012. 
60. Armstrong FD, Thompson RJ Jr, Wang W, Zimmerman R, Pegelow CH, Miller S, Moser F, Bello J, Hurtig A and Vass K: Cognitive functioning and brain magnetic resonance imaging in children with sickle cell disease. Neuropsychology committee of the cooperative study of sickle cell disease. Pediatrics 97: 864-870, 1996

61. Steen RG, Reddick WE, Mulhern RK, Langston JW, Ogg RJ, Bieberich AA, Kingsley PB and Wang WC: Quantitative MRI of the brain in children with sickle cell disease reveals abnormalities unseen by conventional MRI. J Magn Reson Imaging 8: 535-543, 1998

62. Wang W, Enos L, Gallagher D, Thompson R, Guarini L, Vichinsky E, Wright E, Zimmerman R and Armstrong FD; Cooperative Study of Sickle Cell Disease: Neuropsychologic performance in school-aged children with sickle cell disease: A report from the cooperative study of sickle cell disease. J Pediatr 139: 391-397, 2001

63. Hardingham GE and Bading H: Synaptic versus extrasynaptic NMDA receptor signalling: Implications for neurodegenerative disorders. Nat Rev Neurosci 11: 682-696, 2010.

64. Lai TW, Shyu WC and Wang YT: Stroke intervention pathways: NMDA receptors and beyond. Trends Mol Med 17: 266-275, 2011.

65. Wu QJ and Tymianski M: Targeting NMDA receptors in stroke: New hope in neuroprotection. Mol Brain 11: 15, 2018.

66. Chen M, Lu TJ, Chen XJ, Zhou Y, Chen Q, Feng XY, Xu L, Duan WH and Xiong ZQ: Differential roles of NMDA receptor subtypes in ischemic neuronal cell death and ischemic tolerance. Stroke 39: 3042-3048, 2008.

67. Choo AM, Geddes-Klein DM, Hockenberry A, Scarsella D, Mesfin MN, Singh P, Patel TP and Meaney DF: NR2A and NR2B subunits differentially mediate MAP kinase signaling and mitochondrial morphology following excitotoxic insult. Neurochem Int 60: 506-516, 2012.

68. Liu Y, Wong TP, Aarts M, Rooyakkers A, Liu L, Lai TW, Wu DC, Lu J, Tymianski M, Craig AM and Wang YT: NMDA receptor subunits have differential roles in mediating excitotoxic neuronal death both in vitro and in vivo. J Neurosci 27: 2846-2857, 2007.

69. DeRidder MN, Simon MJ, Siman R, Auberson YP, Raghupathi R and Meaney DF: Traumatic mechanical injury to the hippocampus in vitro causes regional caspase- 3 and calpain activation that is influenced by NMDA receptor subunit composition. Neurobiol Dis 22: 165-176, 2006.

70. Eyo UB, Bispo A, Liu J, Sabu S, Wu R, DiBona VL, Zheng J, Murugan M, Zhang H, Tang Y and Wu LJ: The GluN2A subunit regulates neuronal NMDA receptor-induced microglia-neuron physical interactions. Sci Rep 8: 828, 2018.

71. Manzerra P, Behrens MM, Canzoniero LM, Wang XQ, Heidinger V, Ichinose T, Yu SP and Choi DW: Zinc induces a Src family kinase-mediated up-regulation of NMDA receptor activity and excitotoxicity. Proc Natl Acad Sci USA 98: 11055-11061, 2001.

72. Terasaki Y, Sasaki T, Yagita Y, Okazaki S, Sugiyama Y, Oyama N, Omura-Matsuoka E, Sakoda S and Kitagawa K: Activation of NR2A receptors induces ischemic tolerance through CREB signaling. J Cereb Blood Flow Metab 30: 1441-1449, 2010.

73. Zhang X, Zhang Q, Tu J, Zhu Y, Yang F, Liu B, Brann D and Wang R: Prosurvival NMDA 2A receptor signaling mediates postconditioning neuroprotection in the hippocampus. Hippocampus 25: 286-296, 2015.

74. Zhou M and Baudry M: Developmental changes in NMDA neurotoxicity reflect developmental changes in subunit composition of NMDA receptors. J Neurosci 26: 2956-2963, 2006.

75. Hardingham GE, Fukunaga $\mathrm{Y}$ and Bading H: Extrasynaptic NMDARs oppose synaptic NMDARs by triggering CREB shut-off and cell death pathways. Nat Neurosci 5: 405-414, 2002.

76. Lu W, Man H, Ju W, Trimble WS, MacDonald JF and Wang YT: Activation of synaptic NMDA receptors induces membrane insertion of new AMPA receptors and LTP in cultured hippocampal neurons. Neuron 29: 243-254, 2001.

77. Karpova A, Mikhaylova M, Bera S, Bar J, Reddy PP, Behnisch T, Rankovic V, Spilker C, Bethge P, Sahin J, et al: Encoding and transducing the synaptic or extrasynaptic origin of NMDA receptor signals to the nucleus. Cell 152: 1119-1133, 2013.

78. Kaufman AM, Milnerwood AJ, Sepers MD, Coquinco A, She K, Wang L, Lee H, Craig AM, Cynader M and Raymond LA: Opposing roles of synaptic and extrasynaptic NMDA receptor signaling in cocultured striatal and cortical neurons. J Neurosci 32: 3992-4003, 2012.
79. Lau D, Bengtson CP, Buchthal B and Bading $\mathrm{H}$ : BDNF reduces toxic extrasynaptic NMDA receptor signaling via synaptic NMDA receptors and nuclear-calcium-induced transcription of inhba/activin A. Cell Rep 12: 1353-1366, 2015.

80. Wang WY, Jia LJ, Luo Y, Zhang HH, Cai F, Mao H, Xu WC, Fang JB, Peng ZY, Ma ZW, et al: Location- and subunit-specific NMDA receptors determine the developmental sevoflurane neurotoxicity through ERK1/2 signaling. Mol Neurobiol 53: 216-230, 2016.

81. Wang Y, Briz V, Chishti A, Bi X and Baudry M: Distinct roles for $\mu$-calpain and $\mathrm{m}$-calpain in synaptic NMDAR-mediated neuroprotection and extrasynaptic NMDAR-mediated neurodegeneration. J Neurosci 33: 18880-18892, 2013.

82. Ivanov A, Pellegrino C, Rama S, Dumalska I, Salyha Y, Ben-Ari Y and Medina I: Opposing role of synaptic and extrasynaptic NMDA receptors in regulation of the extracellular signal-regulated kinases (ERK) activity in cultured rat hippocampal neurons. J Physiol 572: 789-798, 2006.

83. Wu GY, Deisseroth K and Tsien RW: Activity-dependent CREB phosphorylation: Convergence of a fast, sensitive calmodulin kinase pathway and a slow, less sensitive mitogen-activated protein kinase pathway. Proc Natl Acad Sci USA 98: 2808-2813, 2001.

84. Aarts M, Liu Y, Liu L, Besshoh S, Arundine M, Gurd JW, Wang YT, Salter MW and Tymianski M: Treatment of ischemic brain damage by perturbing NMDA receptor-PSD-95 protein interactions. Science 298: 846-850, 2002.

85. Sattler R, Xiong Z, Lu WY, Hafner M, MacDonald JF and Tymianski M: Specific coupling of NMDA receptor activation to nitric oxide neurotoxicity by PSD-95 protein. Science 284 : 1845-1848, 1999.

86. Pei L, Shang Y, Jin H, Wang S, Wei N, Yan H, Wu Y, Yao C, Wang X, Zhu LQ and Lu Y: DAPK1-p53 interaction converges necrotic and apoptotic pathways of ischemic neuronal death. J Neurosci 34: 6546-6556, 2014.

87. Tu W, Xu X, Peng L, Zhong X, Zhang W, Soundarapandian MM, Balel C, Wang M, Jia N, Zhang W, et al: DAPK1 interaction with NMDA receptor NR2B subunits mediates brain damage in stroke. Cell 140: 222-234, 2010.

88. Ning K, Pei L, Liao M, Liu B, Zhang Y, Jiang W, Mielke JG, Li L, Chen Y, El-Hayek YH, et al: Dual neuroprotective signaling mediated by downregulating two distinct phosphatase activities of PTEN. J Neurosci 24: 4052-4060, 2004.

89. Beschorner R, Adjodah D, Schwab JM, Mittelbronn M, Pedal I, Mattern R, Schluesener HJ and Meyermann R: Long-term expression of heme oxygenase-1 (HO-1, HSP-32) following focal cerebral infarctions and traumatic brain injury in humans. Acta Neuropathol 100: 377-384, 2000.

90. Komkova MA, Karyakina EE and Karyakin AA: Catalytically synthesized prussian blue nanoparticles defeating natural enzyme peroxidase. J Am Chem Soc 140: 11302-11307, 2018.

91. Zhang W, Hu S, Yin JJ, He W, Lu W, Ma M, Gu N and Zhang Y: Prussian blue nanoparticles as multienzyme mimetics and reactive oxygen species scavengers. J Am Chem Soc 138: 5860-5865, 2016.

92. Zhang K, Tu M, Gao W, Cai X, Song F, Chen Z, Zhang Q, Wang J, Jin C, Shi J, et al: Hollow prussian blue nanozymes drive neuroprotection against ischemic stroke via attenuating oxidative stress, counteracting inflammation, and suppressing cell apoptosis. Nano Lett 19: 2812-2823, 2019.

93. Dirnagl U, Klehmet J, Braun JS, Harms H, Meisel C, Ziemssen T, Prass K and Meisel A: Stroke-induced immunodepression: Experimental evidence and clinical relevance. Stroke 38 (Suppl 2): S770-S773, 2007.

94. Sarvari S, Moakedi F, Hone E, Simpkins JW and Ren X: Mechanisms in blood-brain barrier opening and metabolism-challenged cerebrovascular ischemia with emphasis on ischemic stroke. Metab Brain Dis 35: 851-868, 2020

95. Simpkins AN, Dias C, Leigh R, National Institutes of Health Natural History of Stroke Investigators: Identification of reversible disruption of the human blood-brain barrier following acute ischemia. Stroke 47: 2405-2408, 2016.

96. Lakhan SE, Kirchgessner A and Hofer M: Inflammatory mechanisms in ischemic stroke: Therapeutic approaches. J Transl Med 7: 97, 2009.

97. Wang Q, Wei J and Shi Y: Platelet microvesicles promote the recovery of neurological function in mouse model of cerebral infarction by inducing angiogenesis. Biochem Biophys Res Commun 513: 997-1004, 2019. 
98. Rosińska J, Maciejewska J, Narożny R, Kozubski W and Łukasik M: Association of platelet-derived microvesicles with high on-treatment platelet reactivity in convalescent ischemic stroke patients treated with acetylsalicylic acid. Wiad Lek 72 : 1426-1436, 2019.

99. Ghoreishy A, Khosravi A and Ghaemmaghami A: Exosomal microRNA and stroke: A review. J Cell Biochem 120: 16352-16361, 2019.

100. Loffreda A, Nizzardo M, Arosio A, Ruepp MD, Calogero RA, Volinia S, Galasso M, Bendotti C, Ferrarese C, Lunetta C, et al: miR-129-5p: A key factor and therapeutic target in amyotrophic lateral sclerosis. Prog Neurobiol 190: 101803, 2020.

101. Krützfeldt J, Kuwajima S, Braich R, Rajeev KG, Pena J, Tuschl T, Manoharan M and Stoffel M: Specificity, duplex degradation and subcellular localization of antagomirs. Nucleic Acids Res 35: 2885-2892, 2007.

102. Jickling GC, Ander BP, Zhan X, Noblett D, Stamova B and Liu D: microRNA expression in peripheral blood cells following acute ischemic stroke and their predicted gene targets. PLoS One 9: e99283, 2014

103. Shi Y, Li K, Xu K and Liu QH: MiR-155-5p accelerates cerebral ischemia-reperfusion injury via targeting DUSP14 by regulating NF- $\kappa \mathrm{B}$ and MAPKs signaling pathways. Eur Rev Med Pharmacol Sci 24: 1408-1419, 2020

104. Sun H, Zhong D, Wang C, Sun Y, Zhao J and Li G: MiR-298 exacerbates ischemia/reperfusion injury following ischemic stroke by targeting act1. Cell Physiol Biochem 48: 528-539, 2018

105. Liu W, Wang X, Zheng Y, Shang G, Huang J, Tao J and Chen L: Electroacupuncture inhibits inflammatory injury by targeting the miR-9-mediated NF- $\mathrm{BB}$ signaling pathway following ischemic stroke. Mol Med Rep 13: 1618-1626, 2016.

106. Guo D, Ma J, Li T and Yan L: Up-regulation of miR-122 protects against neuronal cell death in ischemic stroke through the heat shock protein 70 -dependent $\mathrm{NF}-\kappa \mathrm{B}$ pathway by targeting FOXO3. Exp Cell Res 369: 34-42, 2018.

107. Block HS and Biller J: Commonly asked questions: Thrombolytic therapy in the management of acute stroke. Expert Rev Neurother 13: 157-165, 2013.

108. Murray V, Norrving B, Sandercock PA, Terént A, Wardlaw JM and Wester P: The molecular basis of thrombolysis and its clinical application in stroke. J Intern Med 267: 191-208, 2010.

109. Röther J, Ford GA and Thijs VN: Thrombolytics in acute ischaemic stroke: Historical perspective and future opportunities. Cerebrovasc Dis 35: 313-319, 2013.

110. Saver JL: Number needed to treat estimates incorporating effects over the entire range of clinical outcomes: Novel derivation method and application to thrombolytic therapy for acute stroke. Arch Neurol 61: 1066-1070, 2004.

111. Saver JL, Gornbein J, Grotta J, Liebeskind D, Lutsep H, Schwamm L, Scott P and Starkman S: Number needed to treat to benefit and to harm for intravenous tissue plasminogen activator therapy in the 3- to 4.5-h window: Joint outcome table analysis of the ECASS 3 trial. Stroke 40: 2433-2437, 2009.

112. Ahmed N, Wahlgren N, Grond M, Hennerici M, Lees KR, Mikulik R, Parsons M, Roine RO, Toni D and Ringleb P; SITS investigators: Implementation and outcome of thrombolysis with alteplase $3-4.5 \mathrm{~h}$ after an acute stroke: An updated analysis from SITS-ISTR. Lancet Neurol 9: 866-874, 2010.

113. Schwamm LH, Ali SF, Reeves MJ, Smith EE, Saver JL, Messe S, Bhatt DL, Grau-Sepulveda MV, Peterson ED and Fonarow GC Temporal trends in patient characteristics and treatment with intravenous thrombolysis among acute ischemic stroke patients at Get With The Guidelines-Stroke hospitals. Circ Cardiovasc Qual Outcomes 6: 543-549, 2013.

114. Wahlgren N, Ahmed N, Davalos A, Ford GA, Grond M, Hacke W, Hennerici MG, Kaste M,Kuelkens S, Larrue V, et al: Thrombolysis with alteplase for acute ischaemic stroke in the safe implementation of thrombolysis in stroke-monitoring study (SITS-MOST): An observational study. Lancet 369: 275-282, 2007.

115. Ingall TJ, O'Fallon WM, Asplund K, Goldfrank LR, Hertzberg VS, Louis TA and Christianson TJH: Findings from the reanalysis of the NINDS tissue plasminogen activator for acute ischemic stroke treatment trial. Stroke 35: 2418-2424, 2004.
116. Jansen O, von Kummer R, Forsting M, Hacke W and Sartor K: Thrombolytic therapy in acute occlusion of the intracranial internal carotid artery bifurcation. AJNR Am J Neuroradiol 16 1977-1986, 1995.

117. Wolpert SM, Bruckmann H, Greenlee R, Wechsler L, Pessin MS and del Zoppo GJ: Neuroradiologic evaluation of patients with acute stroke treated with recombinant tissue plasminogen activator. The rt-PA acute stroke study group. AJNR Am J Neuroradiol 14: 3-13, 1993

118. Mandavia R, Qureshi MI, Dharmarajah B, Head K and Davies AH: Safety of carotid intervention following thrombolysis in acute ischaemic stroke. Eur J Vasc Endovasc Surg 48: 505-512, 2014

119. Furlan AJ and Abou-Chebl A: The role of recombinant pro-urokinase (r-pro-UK) and intra-arterial thrombolysis in acute ischaemic stroke: The PROACT trials. Prolyse in acute cerebral thromboembolism. Curr Med Res Opin 18 (Suppl 2): S44-S47, 2002.

120. Hao C, Ding W, Xu X, Sun Q, Li X, Wang W, Zhao Z and Tang L: Effect of recombinant human prourokinase on thrombolysis in a rabbit model of thromboembolic stroke. Biomed Rep 8: 77-84, 2018.

121. Agrawal A, Golovoy D, Nimjee S, Ferrell A, Smith T and Britz G: Mechanical thrombectomy devices for endovascular management of acute ischemic stroke: Duke stroke center experience. Asian J Neurosurg 7: 166-170, 2012.

122. Deng L, Qiu S, Wang L, Li Y, Wang D and Liu M: Comparison of four food and drug administration-approved mechanical thrombectomy devices for acute ischemic stroke: A network meta-analysis. World Neurosurg 127: e49-e57, 2019.

123. Nogueira RG, Lutsep HL, Gupta R, Jovin TG, Albers GW, Walker GA, Liebeskind DS and Smith WS; TREVO 2 Trialists Trevo versus Merci retrievers for thrombectomy revascularisation of large vessel occlusions in acute ischaemic stroke (TREVO 2): A randomised trial. Lancet 380: 1231-1240, 2012.

124. Saver JL, Jahan R, Levy EI, Jovin TG, Baxter B, Nogueira RG, Clark W, Budzik R and Zaidat OO; SWIFT Trialists: Solitaire flow restoration device versus the merci retriever in patients with acute ischaemic stroke (SWIFT): A randomised, parallel-group, non-inferiority trial. Lancet 380: 1241-1249, 2012.

125. Suzuki K, Matsumaru Y, Takeuchi M, Morimoto M, Kanazawa R, Takayama Y, Kamiya Y, Shigeta K, Okubo S, Hayakawa M, et al: Effect of mechanical thrombectomy without vs with intravenous thrombolysis on functional outcome among patients with acute ischemic stroke: The SKIP randomized clinical trial. JAMA 325: 244-253, 2021.

126. Machado M, Alves M, Fior A, Fragata I, Papoila AL, Reis J and Nunes AP: Functional outcome after mechanical thrombectomy with or without previous thrombolysis. J Stroke Cerebrovasc Dis 30: 105495, 2021.

127. Cirillo C, Le Friec A, Frisach I, Darmana R, Robert L, Desmoulin F and Loubinoux I: Focal malonate injection into the internal capsule of rats as a model of lacunar stroke. Front Neurol 9: 1072, 2018.

128. Fries W, Danek A, Scheidtmann K and Hamburger C: Motor recovery following capsular stroke. Role of descending pathways from multiple motor areas. Brain 116: 369-382, 1993.

129. Haga KK, Gregory LJ, Hicks CA, Ward MA, Beech JS, Bath PW, Williams SC and O'Neill MJ: The neuronal nitric oxide synthase inhibitor, TRIM, as a neuroprotective agent: Effects in models of cerebral ischaemia using histological and magnetic resonance imaging techniques. Brain Res 993: 42-53, 2003.

This work is licensed under a Creative Commons Attribution-NonCommercial-NoDerivatives 4.0 International (CC BY-NC-ND 4.0) License. 